\title{
Therapeutic effect of biosynthetic gold nanoparticles on multidrug-resistant Escherichia coli and Salmonella species isolated from ruminants
}

\author{
Abeer M. Abdalhamed ${ }^{1}\left(\mathbb{D}\right.$, Alaa A. Ghazy ${ }^{1}$, Eman S. Ibrahim² ${ }^{\mathbb{D}}$, Amany A. Arafa ${ }^{(\mathbb{D}}$ and Gamil S. G. Zeedan ${ }^{1}$ \\ 1. Department of Parasitology and Animal Diseases, National Research Centre, Dokki, Egypt; 2. Department of \\ Microbiology and Immunology, National Research Centre, Dokki, Egypt. \\ Corresponding author: Abeer M. Abdalhamed, e-mail: abeerg2007@yahoo.com \\ Co-authors: AAG: aaghazy7@hotmail.com, ESI: dr.eman911@yahoo.com, AAA: gamilzee@yahoo.com, \\ GSGZ: gamilzee@yahoo.com
}

Received: 16-07-2021, Accepted: 22-11-2021, Published online: 29-12-2021

doi: www.doi.org/10.14202/vetworld.2021.3200-3210 How to cite this article: Abdalhamed AM, Ghazy AA, Ibrahim ES, Arafa AA, Zeedan GSG (2021) Therapeutic effect of biosynthetic gold nanoparticles on multidrug-resistant Escherichia coli and Salmonella species isolated from ruminants, Veterinary World, 14(12): 3200-3210.

\begin{abstract}
Background and Aim: Multidrug-resistant (MDR) pathogenic microorganisms have become a global problem in ruminants as a result of the intensive use of antibiotics, causing the development of resistance among gut microbiota. The antibioticresistant microorganisms can be transferred from diseased animals to humans. This study aimed to determine the prevalence of MDR Escherichia coli and Salmonella spp. isolated from cattle, buffaloes, sheep, and goats suffering from respiratory signs, diarrhea, and mastitis and to screen the antibiotic sensitivity of selected isolated bacteria. It also detected antibioticresistance genes by polymerase chain reaction (PCR), produced green gold nanoparticles (AuNPs) using plant extracts (Artemisia herba-alba and Morus alba), and evaluated the antimicrobial activities of these biosynthesized nanoparticles on selected pathogens (E. coli and Salmonella spp.).
\end{abstract}

Materials and Methods: MDR E. coli and Salmonella spp. were investigated using fecal samples (n=408), nasal swabs $(\mathrm{n}=358)$, and milk samples $(\mathrm{n}=227)$ of cattle, buffaloes, sheep, and goats with or without clinical signs, including respiratory manifestations, pneumonia, diarrhea, and mastitis, from different governorates in Egypt. E. coli and Salmonella spp. were isolated and identified on selective media, which were confirmed by biochemical reactions and PCR. Antimicrobial susceptibility testing against 10 commonly used antibiotics was performed using the Kirby-Bauer disk diffusion method. Antibiotic resistance genes bla ${ }_{T E M}$, bla $a_{S H V}$, bla $_{O X A}$, and bla ${ }_{C T X-M}$ were detected by PCR. The antibacterial effect of the biosynthesized AuNPs was evaluated by MIC and well diffusion assay. The biosynthesized AuNPs were also characterized by ultraviolet-visible spectrophotometry and transmission electron microscopy (TEM).

Results: Among all fecal samples, the prevalence of E. coli was 18.4\% (183/993) and that of Salmonella spp. was $16.7 \%$ (66/408), as determined by cultural and molecular tests. All isolates of E. coli and Salmonella spp. were $100 \%$ resistant to ampicillin (AM) and amoxicillin and highly resistant to cefoxitin and AM-sulbactam. The total rate of resistance genes in E. coli was $61.2 \%(112 / 183)$, while that in Salmonella was $63.6 \%(42 / 66)$ for pathogens isolated from ruminants with respiratory manifestations, pneumonia, diarrhea, and mastitis. Among the resistance genes, bla ${ }_{T E M}$ had the highest prevalence rate in $\operatorname{E}$. coli $(25.9 \%, 21 / 81)$ while $b l a_{S H V}$ had the lowest $(9.8 \%, 8 / 81)$ in fecal swabs. AuNPs were successfully synthesized using aqueous leaf extract of $A$. herba-alba and $M$. alba as bioreducing agents. TEM analysis showed particle size of 10-42 nm for $A$. herba-alba and M. alba AuNPs. The biosynthesized AuNPs showed antibacterial activity against MDR E. coli and Salmonella spp.

Conclusion: Rapid and accurate diagnostic methods are the cornerstone for effective treatment to reduce the risk of antimicrobial-resistant pathogenic microorganisms. This is particularly important for overcoming the increasing rate of MDR in ruminants with respiratory manifestations, pneumonia, diarrhea, and mastitis. This can be complemented by the development of AuNPs synthesized in an environmentally friendly manner AuNPs using natural plant extracts for the treatment of antibiotic-resistant microorganisms.

Keywords: Escherichia coli, gold nanoparticle, multidrug-resistant, ruminant, Salmonella species.

\section{Introduction}

The prevalence of multidrug resistance (MDR) is increasing among various pathogenic bacteria

Copyright: Abdalhamed, et al. Open Access. This article is distributed under the terms of the Creative Commons Attribution 4.0 International License (http://creativecommons.org/licenses/ by/4.0/), which permits unrestricted use, distribution, and reproduction in any medium, provided you give appropriate credit to the original author(s) and the source, provide a link to the Creative Commons license, and indicate if changes were made. The Creative Commons Public Domain Dedication waiver (http:// creativecommons.org/publicdomain/zero/1.0/) applies to the data made available in this article, unless otherwise stated. worldwide, leading to antimicrobials no longer being effective for controlling infectious diseases [1]. MDR bacteria are a global problem in ruminants due to the intensive use of antibiotics as growth promoters and for the prevention and treatment of disease [2,3]. The presence of resistant pathogenic strains in dairy cattle, calves, beef cattle, sheep, goats, and feedlot animals constitute the primary reservoir of zoonotic pathogens. Emergent strains of MDR bacteria can be transferred from ruminants to humans through food consumption (meat and milk), or through direct or indirect contact with animals 
or their waste in the environment [4]. Escherichia coli strains isolated from animals are resistant to commonly used antibiotics, which acquire resistance through horizontal gene transfer or gene mutations. They are a major cause of foodborne infections and commonly inhabit the gastrointestinal tract of animals and humans [5]. Salmonella is commonly responsible for enteric bacterial infection of large and small animals, but such infection is more severe in infants from the first 2 weeks to 3 months of life. E. coli and Salmonella species are among the most common and economically damaging pathogens causing diarrhea in neonates of animals used by humans for food [6].

Globally, the $\beta$-lactam antibiotics (cephalosporin, carbapenem, and penicillin) represent about $60 \%$ of all antimicrobial agents used in animals. Their habitual abuse has led to the development of resistance to beta-lactam groups [7]. The recent emergence of MDR E. coli poses a major threat to public health, which is mainly attributed to extended-spectrum beta-lactamases (ESBLs). These enzymes can destroy various $\beta$-lactam antimicrobial agents and are encoded by specific ESBL genes, such as $b l a_{T E M}$ (encoded for penicillin resistance), $b l a_{K P C}$ (encoded for carbapenems resistance), and $b l a_{\text {CTX }}$ (encoded for cephalosporin resistance). The emergence of MDR virulent $E$. coli has become a global health concern $[8,9]$. Most of the $\beta$-lactam resistance in Salmonella is provided by horizontally acquired $\beta$-lactamases. However, many other bacteria have intrinsic ampC, bla $a_{\text {TEM }}$, bla $a_{\mathrm{CTX}-\mathrm{M}}, b l a_{I M P}$, $b l a_{V I M}, b l a_{K P C}, b l a_{S H V}$, and bla ${ }_{O X A}[10]$. MDR strains such as Salmonella spp. and E. coli are not susceptible to many antibiotics, so alternative treatments using green nanoparticles (NPs) are required to eliminate them [11].

The green synthesis of NPs has attracted substantial interest among scientists. Plant extracts are a promising tool for the green synthesis of NPs, given their convenience, ease of use, environmentally friendly nature, and the minimization of the harmful biohazardous effects of chemical and physical methods, along with the avoidance of toxic chemicals and dangerous by-products. Green-synthesized NPs have biocidal effects against Gram-positive and Gram-negative bacteria that cause different diseases in animals $[12,13]$. Moreover, antibiotics selectively target bacteria, while gold and silver NPs exhibit fairly broad-spectrum activity. AuNPs act by destroying the cell membrane or by inhibiting the binding of tRNA to the small subunit of the ribosome, leading to the suppression of protein synthesis [14]. It has also been reported that NPs display effective inhibitory activity against resistant strains such as ampicillin (Am)-resistant E. coli [15]. Given their stability and antibacterial activity, synthesized gold NPs (AuNPs) are promising for biomedical applications [16]. Effective treatment of MDR bacteria requires the rapid and accurate diagnosis of their presence using phenotypes, along with molecular methods to detect the presence of resistance genes [17]. A number of novel approaches for the use of green NPs to combat bacterial resistance are currently available [18].

The present study aimed to evaluate the therapeutic effect of biosynthetic AuNPs developed using a mixture of Artemisia herba-alba and Morus alba leaf extract against MDR E. coli and Salmonella spp. isolated from ruminants (cattle, buffaloes, sheep, and goats) with clinical signs including respiratory manifestations, pneumonia, diarrhea, and mastitis.

\section{Materials and Methods}

\section{Ethical approval}

All methods were performed in accordance with relevant guidelines and regulations. Well-trained experts conducted the handling of animals and experimental procedures. The handling of animals and all protocols were approved by the Animal Ethics Review Committee of National Research Centre, Egypt, under approval number \#19-149\#.

\section{Study period, area, and sample collection}

The study was conducted from December 2019 to March 2021. A total of 358 nasal and 408 fecal swab samples and 227 milk samples were collected from cattle, buffaloes, sheep, and goats in different governorates in Egypt (Monofia, Giza, Beni-Suef, Alexandria, Siwa, and Marsa Matruh). This included animals with or without clinical signs, including respiratory manifestations, pneumonia, diarrhea, and mastitis. Nasal swabs were collected $(n=358)$ from cattle $(n=38)$, buffaloes $(n=40)$, sheep $(n=155)$, and goats $(n=125)$. Meanwhile, fecal samples $(\mathrm{n}=408)$ were collected from cattle $(n=52)$, buffaloes $(n=116)$, sheep $(n=135)$, and goats $(n=105)$. Moreover, milk samples $(n=227)$ were collected from cattle $(n=54)$, buffaloes $(n=36)$, sheep $(n=62)$, and goats $(n=75)$. Nasal and rectal/fecal swabs collected in sterile sample tube contained sterile saline or PBS. The samples were transported in ice box and stored between $4^{\circ} \mathrm{C}-8^{\circ} \mathrm{C}$ for up to 72 hours after collection and milk sample was divided into 2 aliquots: the first was plated fresh for bacteriological culture, to isolate and identify E. coli and Salmonella., While, the second milk sample was frozen at $-20^{\circ} \mathrm{C}$ for bacteriological culture, and DNA extraction for molecular diagnosis. All samples were subjected to detect resistance genes.

\section{Isolation and identification of $E$. coli}

All samples (358 nasal swab, 408 fecal swab, and 227 milk samples) collected from cattle, buffaloes, sheep, and goats with clinical signs including respiratory manifestations, pneumonia, and diarrhea were placed on peptone water broth (Oxoid, UK) as pre-enrichment for bacterial growth, in accordance with the methods described previously [19]. A loopful of culture inoculate was streaked on MacConkey (Oxoid) agar. Pink colonies obtained from MacConkey agar that was indole-positive were considered positive for E. coli and maintained at $-20^{\circ} \mathrm{C}$ in $20 \%$ glycerol brain 
heart infusion broth for further confirmation and characterization by polymerase chain reaction (PCR) and antibiotic susceptibility testing, in accordance with a previous study [20].

\section{Isolation and identification of Salmonella spp.}

Fecal swabs were collected from cattle, buffaloes, sheep, and goats with clinical signs including respiratory manifestations, pneumonia, and diarrhea $(\mathrm{n}=408)$ and pre-enriched on BPW (Oxoid), incubated at $37^{\circ} \mathrm{C}$ for $16 \mathrm{~h}$. One milliliter of inoculum was transferred into selenite cystine broth (Oxoid) after pre-enrichment, as described previously [21]. A loopful of inoculum was also plated onto xylose lysine deoxycholate (XLD) (Oxoid) medium and incubated at $37^{\circ} \mathrm{C}$ for $24 \mathrm{~h}$. Each colony with a black center from XLD was inoculated in brilliant green agar (Oxoid) and incubated. Triple sugar iron, urease, and citrate tests were performed for the confirmation of Salmonella spp. and further confirmation and characterization were carried out by PCR and antibiotic susceptibility testing, as described previously [22].

\section{DNA extraction by different methods}

DNA extraction was carried out by different heating methods (boiling, microwaving, and heat block). Briefly, a pure colony collected from freshly grown culture was initially placed in an Eppendorf tube containing molecular-grade water $(100 \mu \mathrm{L})$ followed by mixing gently through vortexing. Subsequently, the mixture was heated for $10 \mathrm{~min}$, cooled for $10 \mathrm{~min}$, and centrifuged for $10 \mathrm{~min}$ at $1400 \mathrm{rpm}$. Finally, the supernatant was collected as the source for the genomic DNA for PCR and stored at $-20^{\circ} \mathrm{C}$ until further use.

The PCR reaction was carried out in a final volume of $25 \mu \mathrm{L}$ with $12.5 \mu \mathrm{L}$ of master mix $(2 \times)$ (Promega, Madison, WI, USA), $4 \mu \mathrm{L}$ of genomic DNA $(50 \mathrm{ng} / \mu \mathrm{L}), 1 \mu \mathrm{L}$ of each primer, and $6.5 \mu \mathrm{L}$ of nuclease-free water. After amplification, PCR products were subjected to gel electrophoresis in $1.5 \%$ agarose, followed by staining and visualization with $0.25 \%$ ethidium bromide solution and an ultraviolet transilluminator. A DNA ladder (100 bp; Promega) was used to assess the sizes of the PCR amplicons.

\section{Molecular confirmation of isolated $E$. coli and Salmonella spp.}

Isolated E. coli and Salmonella spp. were confirmed by PCR targeting an E. coli (LTI) gene and a Salmonella genus-specific ( $\mathrm{fm} A)$ gene, as shown in Table-1, in accordance with a previous study [23].

\section{Antimicrobial sensitivity test (AST)}

The isolated E. coli and Salmonella spp. were subjected to AST using the disk diffusion technique, in accordance with the guidelines of the Clinical and Laboratory Standards Institute [24,25]. The testing involved 10 commonly used antibiotics, including three groups: A quinolone group (levofloxacin: LEV [5 $\mu \mathrm{g} /$ disk] and ciprofloxacin: CIP [5 $\mu \mathrm{g} / \mathrm{disk}]$ ); a beta-lactam group (amoxicillin: Ax [25 $\mu \mathrm{g} /$ disk], Am [10 $\mu \mathrm{g} / \mathrm{disk}]$, cefoxitin: CX [30 $\mu \mathrm{g} / \mathrm{disk}]$, imipenem:
IMP [10 $\mu \mathrm{g} /$ disk], cefotaxime: CTX [30 $\mu \mathrm{g} / \mathrm{disk}]$, and Am/sulbactam: SAM); and an aminoglycoside group (gentamicin: CN [10 $\mu \mathrm{g} / \mathrm{disk}$ ], [20 $\mu \mathrm{g} / \mathrm{disk}$ ], and amikacin: AK [30 $\mu \mathrm{g} /$ disk]), following the disk diffusion method described previously [25]. Finally, the zone of growth inhibition was compared using standards provided elsewhere [26] to identify the resistant isolates. Isolates showing resistance to three or more different classes of antibiotics were defined as MDR [27].

Detection of resistance genes in MDR $E$. coli and Salmonella spp. isolated from diseased animals by PCR

The status of bacteria with multidrug resistance against beta-lactams (Am, Ax, Am/sulbactam, and CX) as determined by AST was further confirmed by the detection of resistance genes ( $b l a_{T E M}, b l a_{S H V m}$, bla ${ }_{O X A}$, and $b l a_{C T X-M}$ ) using PCR, in accordance with a previous study [28], using the resistance gene primers listed in Table-2.

\section{Preparation of A. herb-alba and alba aqueous leaf extracts}

The preparation of leaf extracts was carried out in accordance with a previous study [29]. A. herba-alba and M. alba leaves were washed using double-distilled water, air-dried, and then each dried plant was ground separately into a fine powder. Briefly, $10 \mathrm{~g}$ of powder from each of $A$. herba-alba and M. alba was dissolved in $100 \mathrm{~mL}$ of double-distilled water in a conical flask. The solution was boiled at $70-80^{\circ} \mathrm{C}$ for $15-20 \mathrm{~min}$ in a water bath. The solution was then filtered at room temperature $(25 \mathrm{oC})$ and stored at $4^{\circ} \mathrm{C}$ for further analysis.

\section{Biosynthesis of AuNPs}

AuNPs were synthesized using A. herba-alba and $M$. alba leaf extracts. Specifically, $10 \mathrm{~mL}$ of A. herba-alba and M. alba leaf extract (v/v) was mixed with $90 \mathrm{~mL}$ of $1 \mathrm{mM}$ aqueous solution of gold chloride $\left(\mathrm{HAuCl}_{4}\right)$ and left at $25 \mathrm{oC}$ to react. After 20 min, a change in the color of the solution from yellow to purple/red was identified, which signified the reduction of $\mathrm{Au}^{3+}$ to $\mathrm{Au}^{0} \mathrm{NPs}$. The resulting AuNPs were incubated at $25^{\circ} \mathrm{C}$ for $24 \mathrm{~h}$ and then purified by centrifugation at $10080 \mathrm{xg}$ for $15 \mathrm{~min}$. The pellet was purified by several washes in distilled water and then transferred to a Petri dish for drying overnight at $30^{\circ} \mathrm{C}$.

\section{Characterization of AuNPs}

The wavelength with maximum absorption of the obtained NPs was measured by UV-spectra. The size distribution and shape of the colloidal AuNPs were studied by SEM and transmission electron microscopy (TEM).

\section{Antimicrobial assay for AuNPs}

The antimicrobial activity was analyzed using the agar well diffusion method [30]. The samples were maintained in broth and subcultured in a Petri dish before testing. First, $100 \mu \mathrm{L}$ of $A$. herba-alba and M. alba AuNPs were loaded into each well on Mueller-Hinton (MH) agar plates. These plates were subsequently sealed and incubated face upwards in an incubator at $37 \pm 0.2^{\circ} \mathrm{C}$ for $24 \mathrm{~h}$. The appearance of a 
Table-1: List of primers used for detecting E. coli and Salmonella spp.

\begin{tabular}{lll}
\hline Isolated bacteria & Target genes & Primer sequence $\mathbf{( 5 ^ { \prime } \rightarrow \mathbf { 3 } ^ { \prime } )}$ \\
\hline Salmonella spp. & $f m A$ & (F) 5 -CCT TTC TCC ATC GTCCTG AA-3, \\
E. coli & $L T I$ & (R) 5 -TGC TGT TAT CTG CCT GAC CA-3 \\
& & (F) 5-AGCAGGTTCCCAC CGGATCACCA-3, \\
\hline
\end{tabular}

E. coli=Escherichia coli

Table-2: Oligonucleotide primers of $\beta$-lactamase resistance genes of isolated E. coli and and Salmonella spp.

\begin{tabular}{|c|c|c|c|}
\hline Genetic resistance factors & Genes & Primer sequence $\left(5^{\prime} \rightarrow 3^{\prime}\right)$ & Size (bp) \\
\hline \multirow[t]{4}{*}{$\beta$-lactam genes (b/a) } & $b l a_{T E M}$ & $\begin{array}{l}\text { F: ATG AGT ATT CAA CAT TTC CG } \\
\text { R: CCA ATG CTT ATT CAG TGA GG }\end{array}$ & 1080 \\
\hline & $b l a_{S H V}$ & $\begin{array}{l}\text { F : TTA TCT CCC TGT TAG CCA CC } \\
\text { R: GAT TTG CTG ATT TCG CTC GG }\end{array}$ & 768 \\
\hline & bla $_{\mathrm{OXA}}$ & $\begin{array}{l}\text { F: ATG AAA AAC ACA ATA CAT ATC } \\
\text { R: AAT TTA GTG TGT TTA GAA TGG }\end{array}$ & 813 \\
\hline & bla $_{C T X-M}$ & $\begin{array}{l}\text { F: -ATG TGC AGY ACC AGT AAR GT } \\
\text { R: -TGG GTR AAR TAR GTS ACC AGA }\end{array}$ & 544 \\
\hline
\end{tabular}

E. coli=Escherichia coli

clear/white area around the wells was recorded and measured (in millimeters).

\section{Growth of bacteria at different concentrations of bio- synthetic AuNPs}

E. coli and Salmonella suspensions $(0.2 \mathrm{~mL})$ were inoculated into corresponding tubes containing $1.5 \mathrm{~mL}$ of different concentrations of $A$. herba-alba, M. alba, and $A$. herba-alba+M. alba AuNPs, and $1.5 \mathrm{~mL}$ of MHB. To these test tubes, $1 \mathrm{~mL}$ of phenol red indicator solution was added. Tubes containing inoculum alone served as positive controls and tubes with different biosynthetic NPs+nutrient media served as negative controls. Test tubes with only MHB served as a blank control. The tubes were incubated at $37^{\circ} \mathrm{C}$ for $24 \mathrm{~h}$ and were observed for changes in color and $\mathrm{pH}$.

\section{Statistical analysis}

SPSS software version 20.0 (IBM, USA) was used to analyze the data. Frequency and mean were estimated using descriptive analysis.

\section{Results}

Prevalence of $E$. coli and Salmonella spp. in investigated animals

Isolates of E. coli and Salmonella spp. from animals with respiratory manifestations, pneumonia, diarrhea, and mastitis were identified and characterized based on their morphology, biochemically identified, and confirmed by molecular assays. The bacteriological analysis included microscopic analysis. In this analysis, the bacterial isolates that were Gramnegative bacilli of moderate size and produced pink colonies on MacConkey agar were designated as $E$. coli, while the black-centered colonies on XLD were designated as Salmonella spp. All E. coli isolates were identified by biochemical tests, showing positivity in catalase, lactose fermentation, indole, and methyl red tests. They were also negative in cytochrome oxidase, Voges-Proskauer, citrate utilization, $\mathrm{H}_{2} \mathrm{~S}$ production, and urease tests. The bacteriological analysis and molecular assays showed positivity for E. coli in $18.4 \%(183 / 993)$ of all samples. The prevalence of $E$. coli was $5.02 \%(18 / 358)$ from nasal samples of the different animals, while it was $19.8 \%(81 / 408)$ from fecal swabs and 37\% (84/227) from milk samples. Meanwhile, the total prevalence of Salmonella spp. in fecal swabs collected from different animals was $16.17 \%$ (66/408). In fecal samples, the highest prevalence of Salmonella spp. was $26.9 \%(14 / 52)$ in cattle, while the lowest was $10.34 \%(12 / 116)$ in buffaloes, as shown in Table-3.

\section{Detection of beta-lactam resistance genes by PCR}

The isolated E. coli $(\mathrm{n}=183)$ and Salmonella spp. $(\mathrm{n}=66)$ were screened by PCR to detect antibiotic resistance genes. The total resistance to $E$. coli and Salmonella spp. detected by PCR was $61.2 \%$ $(112 / 183)$, for beta-lactam genes in E. coli and Salmonella was $63.6 \%$. (42/66). The highest percent of bla ${ }_{T E M}$ resistance genes had the highest prevalence, which was present at a rate of $25.9 \%(21 / 81)$, while the lowest rate was for $b l a_{S H} \mathrm{~V}$, present at a rate of 9.8\% (8/81), as shown in Figures- 1 and 2.

\section{Biosynthesis of A. herba-alba and M. alba AuNPs}

The successful biosynthesis of A. herba-alba and $M$. alba AuNPs was achieved by adding a mixture of $A$. herba-alba and M. alba leaf extract to an aqueous solution of gold chloride $\left(\mathrm{HAuCl}_{4}\right)$. This was indicated by a change in the color of the solution from yellow to purple/dark red and dark brown, signifying the reduction of $\mathrm{Au}^{3+}$ to $\mathrm{Au}^{0}$ NPs (Figure-3).

\section{Ultraviolet-visible (UV-Vis) spectral analysis}

The reduction of aqueous $\mathrm{HAuCl}_{4}$ ions during the reaction with $A$. herba-alba and $M$. alba extract was followed by UV-Vis spectroscopy and modification using spectrophotometry/96-well ELISA reader (ODs). 
Table-3: Prevalence of E. coli and Salmonella spp. in different animals.

\begin{tabular}{|c|c|c|c|c|c|c|}
\hline \multirow[t]{2}{*}{ Samples } & \multirow[t]{2}{*}{ Species } & \multirow[t]{2}{*}{ No. of samples } & \multicolumn{2}{|c|}{ E. coli } & \multicolumn{2}{|c|}{ Salmonella spp. } \\
\hline & & & + ve & $\%$ & $+v e$ & $\%$ \\
\hline \multirow[t]{5}{*}{ Nasal samples } & Cattle & NS $(n=38)$ & 2 & 5.2 & & \\
\hline & Buffaloes & $\mathrm{NS}=(40)$ & 2 & 5 & & \\
\hline & Sheep & $N S=(155)$ & 6 & 3.8 & & \\
\hline & Goats & $N S=(125)$ & 8 & 6.4 & & \\
\hline & Total & 358 & 18 & 5.02 & & \\
\hline \multirow[t]{5}{*}{ Fecal samples } & Cattle & $\mathrm{FS}=(52)$ & 11 & 21.1 & 14 & 26.9 \\
\hline & Buffaloes & $\mathrm{FS}=(116)$ & 22 & 18.9 & 12 & 10.34 \\
\hline & Sheep & $\mathrm{FS}=(135)$ & 23 & 17 & 22 & 16.29 \\
\hline & Goats & $\mathrm{FS}=(105)$ & 25 & 23.8 & 18 & 17.14 \\
\hline & Total & 408 & 81 & 19.8 & 66 & 16.17 \\
\hline \multirow[t]{5}{*}{ Milk samples } & Cattle & Milk=(54) & 16 & 29.6 & & \\
\hline & Buffaloes & Milk=(36) & 16 & 44.4 & & \\
\hline & Sheep & Milk $=(62)$ & 21 & 33.8 & & \\
\hline & Goats & Milk=(75) & 31 & 41.3 & & \\
\hline & Total & 227 & 84 & 37 & & \\
\hline Total isolates & & 993 & 183 & 18.4 & 66 & 16.17 \\
\hline
\end{tabular}

NS=Nasal swab, $\mathrm{FS}=$ Fecal swab, $\mathrm{MS}=$ Milk sample. . coli=Escherichia coli

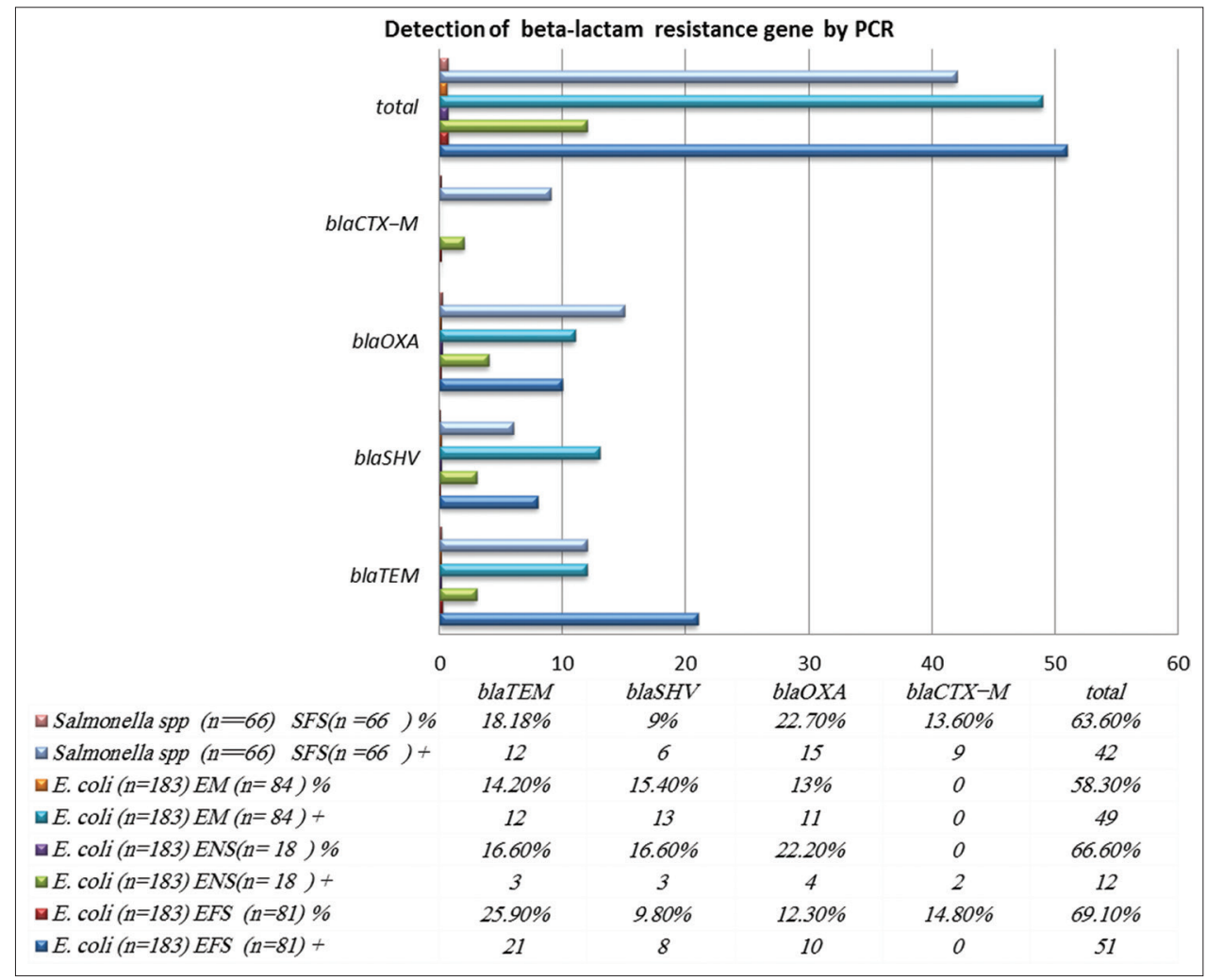

Figure-1: Detection of beta-lactam resistance genes by polymerase chain reaction (PCR). EFS=Escherichia coli isolated from fecal samples. ENS=Escherichia coli isolated from nasal swabs. EMS=Escherichia coli isolated from milk samples. $\mathrm{SFS}=$ Salmonella spp. isolated from fecal samples.

Characterization of A. herb-alba and M. alba AuNPs using TEM

Antibacterial effect of biosynthetic AuNPs using well diffusion assay.

\section{Discussion}

Antibiotics are widely used in animals at subtherapeutic doses to promote growth, and for the treatment of disease, resulting in the development of microbial resistance against these agents [31]. The current study determined the prevalence of virulence genes, namely, the beta-lactam resistance genes bla TEM $_{\text {, }}$ bla $_{S H V M}$, bla $a_{O X A}$, and bla ${ }_{C T X-M}$, in E. coli and Salmonella spp. isolated from nasal and fecal swabs and milk samples of cattle, buffaloes, sheep, and goats with clinical signs including respiratory manifestations, pneumonia, diarrhea, and mastitis. It also evaluated the inhibitory effects of AuNPs synthesized using A. herba-alba and M. alba leaf extracts. Our results demonstrated that E. coli was present at a rate of $5.02 \%$ in nasal samples, $19.8 \%$ in fecal samples, and $37 \%$ in milk samples, as shown 


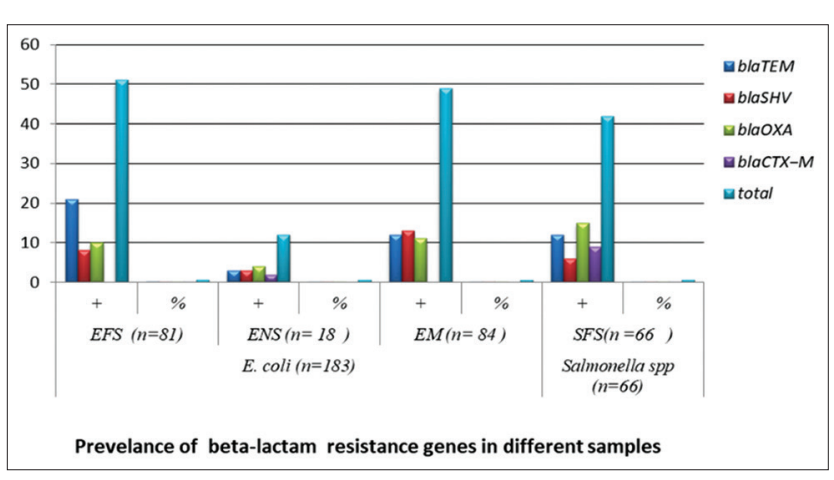

Figure-2: Prevalence of beta-lactam resistance genes in different samples. EFS=Escherichia coli isolated from fecal samples. ENS=Escherichia coli isolated from nasal swabs. EMS=Escherichia coli isolated from milk samples. $\mathrm{SFS}=$ Salmonella spp. isolated from fecal samples.

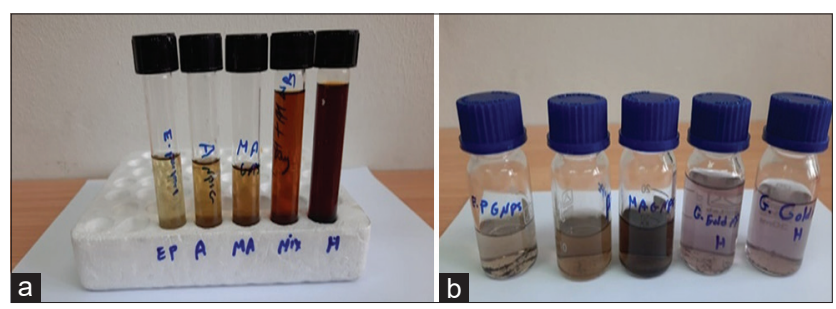

Figure-3: ( $a$ and $b$ ) Observation of the color changes confirming AuNP formation in the reaction mixture at different time points from left to right: Pale yellow, light pink, light red and dark red, dark brown, and purple. The successful biosynthesis of Artemisia herb-alba and Morus alba AuNPs was achieved by adding a mixture of $A$. herbaalba and M. alba leaf extract to an aqueous solution of gold chloride $\left(\mathrm{HAuCl}_{4}\right)$, as indicated by a change in solution color from yellow to purple/dark red and dark brown, signifying the reduction of $\mathrm{Au}^{3+}$ to $\mathrm{Au}^{0} \mathrm{NPs}$.

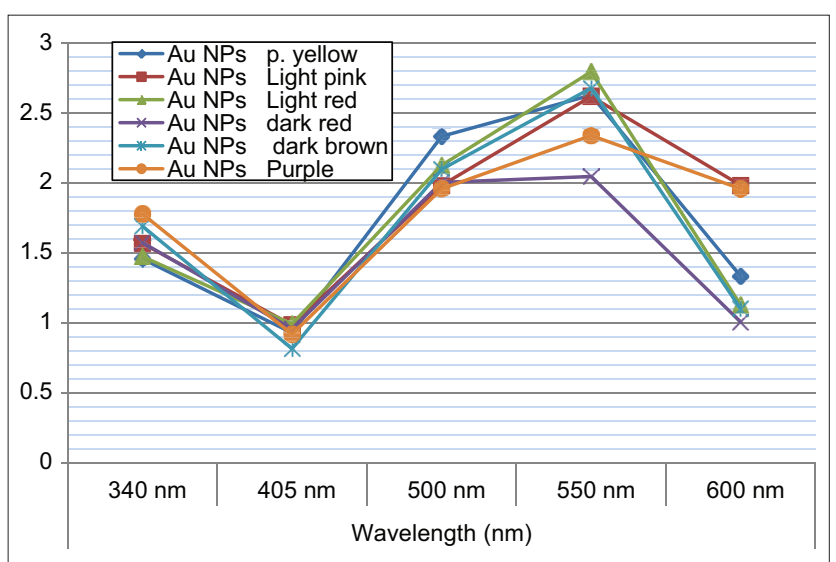

Figure-4: Ultraviolet spectra for Artemisia herb-alba and Morus alba AuNPs of different sizes and colors in colloidal solution. Strong resonance at 520-570 nm is clearly seen and arises due to the excitation of surface plasmon vibrations in the gold nanoparticles. The formation of gold nanoparticles (AuNPs) was confirmed using an ultravioletvisible spectrophotometer at a wavelength of 520-570 nm based on surface plasmon resonance. The findings showed that the concentration and utilization of $A$. herb-alba and M. alba leaf extracts facilitated the production and strongly affected the optical properties of the AuNPs.

in Table-3. These results are in agreement with a previous study conducted by Amat [32]. E. coli is known to be a common opportunistic pathogen that causes several types of infection, causing diarrhea, mastitis, septicemia, and respiratory manifestations. In this work, the lowest positivity rates for E. coli were $3.8 \%, 5 \%, 5.2 \%$, and $6.4 \%$ from nasal swabs of sheep, buffaloes, cattle, and goats, respectively (Table-3). This finding is in agreement with the previous studies $[32,33]$ that found that $E$. coli was present at a low rate of $4.22 \%$ in healthy and diseased animals with respiratory signs. In addition, it was reported [34] that the rate of bacteria in the bovine nasopharyngeal tract was very low compared with the rates at other anatomical sites [35]. Another study explained the presence of virulence genes in extraintestinal E. coli [36]. The finding in the present work of the pathogenicity of $E$. coli isolated from nasal swabs of ruminants with respiratory signs may be associated with the inhalation of a number of bacteria from the environment [37]. The findings of the current study (Table-3) indicate that E. coli was detected at the highest rates of 25/105 (23.8\%) and $11 / 52(21.1 \%)$ from fecal swabs of goats and cattle with diarrhea, while Salmonella spp. were identified at the highest rate of $14 / 52(26.9 \%)$ from fecal samples of cattle. These findings are in agreement with a previous study of Das et al., [38] who found E. coli at a rate of $30 \%$ in cattle in Egypt but conflict with the results with Zeedan et al. [39]. Moreover, in another study, E. coli was identified in both diarrheic sheep and goats $(34.7 \%$ and $30.7 \%)$, while Salmonella species were found at a rate of $3.6 \%$ in sheep and $2.6 \%$ in goats in Saudi Arabia [40]. Furthermore, in fecal samples collected from cattle in India, it was reported as $19 \%$ [41].

The observed variations in the prevalence of pathogenic bacteria in ruminants with clinical respiratory signs, diarrhea, and mastitis may be due to the studies focusing on different geographic areas, along with variations in animal management, in agreement with the previous studies $[40,42]$. The highest rate of positivity for $E$. coli in fecal samples and milk rather than in nasal swab samples (Table-3) may be due to the commonly found pathogenic E. coli in animal feces and shedding in manure or dung into the soil, leading to intense contamination with bacteria [43]. The highest rates of positivity of E. coli were $16 / 36$ (44.4\%) and $31 / 75(41.3 \%)$ from milk samples of buffaloes and goats, respectively, as shown in Table-3, in agreement with many previous studies [44-46]. The inappropriate treatment of animal disease may thus cause the transmission of E. coli and Salmonella spp. The misuse of antibiotics in the veterinary field to prevent and control bacterial diseases in animals may have led to the development of resistance against these agents [47].

As shown in Table-4, E. coli and Salmonella spp. were $100 \%$ resistant to Am and Ax. In addition, both isolates were highly resistant to CX and Am/SAM, at rates of $86.4 \%$ and $81.8 \%$ for Salmonella spp. and $87.4 \%$ and $82.5 \%$ for E. coli. Meanwhile, both 
isolates were highly susceptible to IMP, cefotaxime, LEV, CIP, gentamicin, and amikacin, which are in agreement with the previous reports [38,48]. Isolated MDR E. coli with resistance to Am, Ax, Ax-clavulanic acid, and cefotaxime harbor the $b l a_{\mathrm{TEM}}, b l a_{C T X}$, and $b l a_{\mathrm{KPC}}$ resistance genes in Egypt. In addition, in a previous study [49], Salmonella spp. were isolated from livestock animals in South Africa with high rates of resistance to $\mathrm{Am}$ and $\mathrm{Ax}$-clavulanate $(64 \%$ and $63 \%$, respectively). Am and Ax are intensively used for treating different animal infections in cattle, sheep, and goats [50].

On farms, antibiotics tend to be administered to all animals during the treatment of different diseases, which promotes antibiotic resistance and has harmful effects on the intestinal microflora of healthy animals. Other antibiotics such as fluoroquinolones and beta-lactams

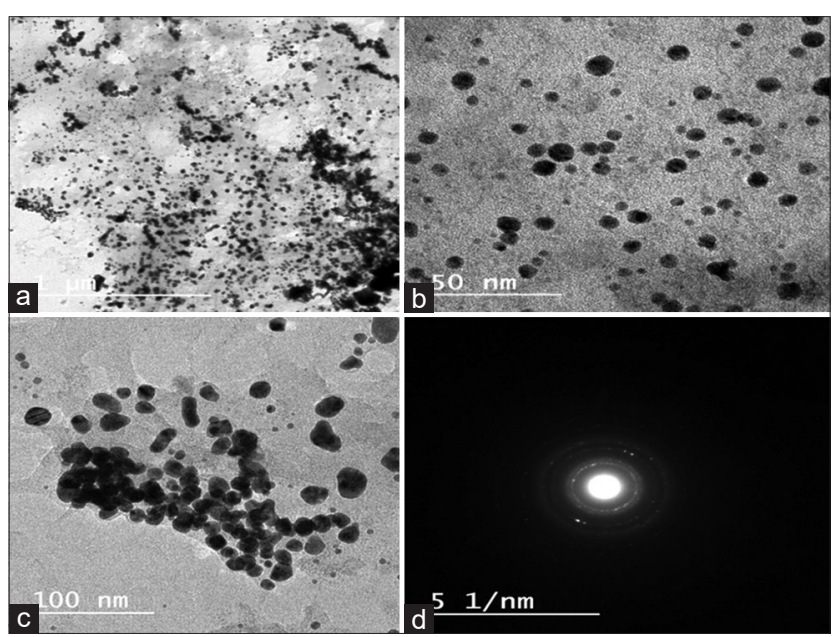

Figure-5: TEM micrographs of Artemisia herba-alba and Morus alba gold nanoparticles (AuNPs) of different sizes and shapes. A histogram of their distribution is shown in (a), with colloidal AuNPs being small and spherical, while aggregations have an average size of $\sim 10$. (b) The agglomeration of AuNPs was lower than the last one and the particle size was between 12 and $20 \mathrm{~nm}$, showing almost spherical and separated particles. (c) Particle sizes were between 20 and $42 \mathrm{~nm}$, with a rod-like appearance. The results suggest that the appearance of smaller particle size synthesized with large size nanoparticles is due to mixing aqueous extracts of $A$. herb-alba and M. alba.

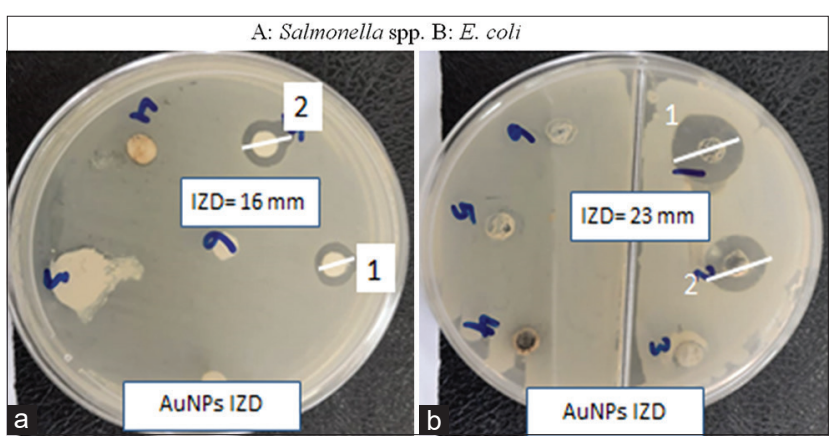

Figure-6: Evaluation of the inhibitory effect of Artemisia herba-alba and Morus alba gold nanoparticles (AuNPs) by well diffusion test. (a) Salmonella spp. and (b) Escherichia coli showing inhibition zone diameter of 16 and $23 \mathrm{~mm}$, respectively. are used as growth promoters on farms, leading to bacterial resistance in Salmonella spp. and E. coli [49-51]. Therefore, antibacterial agents should only be used in the veterinary and health sectors following accurate diagnoses, along with the routine application of AST [52]. Overall, in this study, resistance genes were found in E. coli at a rate of $61.2 \%$ and in Salmonella at $63.6 \%$, as shown in Figures-1 and 2, which is in agreement with a previous study [53] demonstrating rates of resistant $E$. coli and Salmonella spp. of $60 \%$ and 50\%, respectively, in the developing countries, they showed a resistance rate $>50 \%$. Among the resistance genes, the highest rate was found for $b l a_{T E M}(21 / 81,25.9 \%)$ in E. coli fecal swabs, while the lowest was for bla ${ }_{S H V}(8 / 81,9.8 \%)$ in $E$. coli nasal swabs, as shown in Figures-1 and 2. The high resistance may be due to the excessive use of antibiotics, in agreement with a previous study of Oguninu et al. [54]. The prevalence of $b l a_{C M Y-2}$ was $38.88 \%$ by Dong et al. [55]. The high prevalence of beta-lactam degrading genetic determinants may be due to the widespread use of extended beta-lactams such as Am and Ax for treating infections in cattle $[49,56]$. A possible explanation for the findings is that the feeding of animals on foods mixed with antibiotics as growth promoters has increased the rate of bacterial resistance [49]. $b a_{C M Y-2}$ is involved in cell wall synthesis and membrane transport activity. The bla $a_{T E M-1}$ and bla ${ }_{C M Y-2}$ resistance genes in bacteria cause the degradation of beta-lactams and extended beta-lactams, which could explain their association. bla $a_{T E M-1}$ and bla $a_{C M Y-2}$ are located on transferable plasmids [57].

Antibiotic resistance is mediated by genetic elements through different mechanisms, leading to the escape of bacteria from the effects of antibiotics [58]. A previous study by Awosile [59] found that the beta-lactam $\left(b l a_{T E M-1}\right.$ and $\left.b l a_{\mathrm{CMY}-2}\right)$ resistance genes encode enzymes that degrade beta-lactam antibiotics by hydrolyzing the beta-lactam ring. This is in agreement with our study that showed phenotypic resistance to beta-lactam antibiotics in E. coli and Salmonella spp. through the bla ${ }_{T E M}, b l a_{S H V}, b l a_{O X A}$, and bla $_{C T X-M}$ resistance genes.

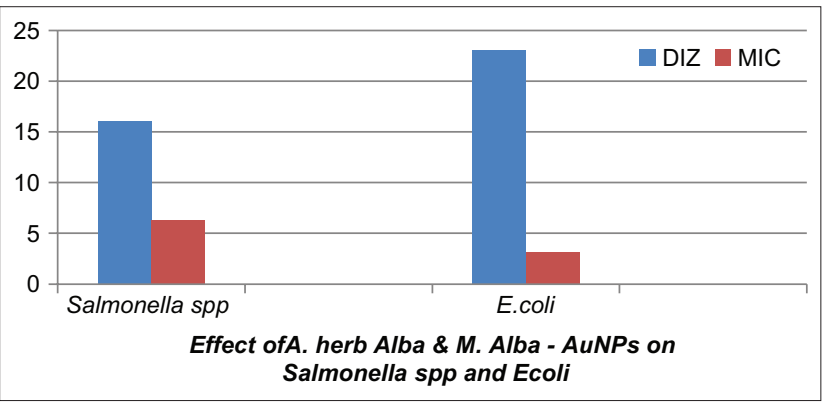

Figure-7: The inhibitory effect of biosynthetic Artemisia herb-alba and Morus alba gold nanoparticles (AuNPs), showing antibacterial activity against isolated bacteria. The inhibitory effects (IZD and MIC) of $A$. herba-alba and $M$. alba AuNPs on Salmonella spp. were $16 \mathrm{~mm}$ and $6.25 \mathrm{~g} / \mathrm{mL}$, and those on Escherichia coli were $23 \mathrm{~mm}$ and $3.125 \mathrm{~g} / \mathrm{mL}$, respectively. IZD: Inhibition zone diameter, MIC: Minimal inhibitory concentration. 
Table-4: Antimicrobial susceptibility pattern of E. coli and Salmonella spp. isolated from clinical samples of different animals.

\begin{tabular}{|c|c|c|c|c|c|}
\hline \multirow[t]{2}{*}{ Antibiotic class } & \multirow[t]{2}{*}{ Antibiotic } & \multicolumn{2}{|c|}{ Salmonella spp. $(n=66)$} & \multicolumn{2}{|c|}{ E. coli $(n=183)$} \\
\hline & & $\mathbf{S}$ & $\boldsymbol{R}$ & $\mathbf{S}$ & $\boldsymbol{R}$ \\
\hline \multirow[t]{6}{*}{ Beta-lactams } & $A x(25 \mu g)$ & $0 \%(0)$ & $100 \%(66) *$ & $0 \%(0)$ & $100 \%(183) \mathrm{A}$ \\
\hline & $\mathrm{Am}(10 \mu \mathrm{g})$ & $0 \%(0)$ & $100 \%(66 *)$ & $0 \%(0)$ & $100 \%(183) \mathrm{B}$ \\
\hline & Fox $(30 \mu \mathrm{g} /$ disk $)$ & $13.6 \%(9)$ & $86.4 \%(57)$ & $12.56 \%(23)$ & $87.4 \%(160)$ \\
\hline & IMP $(10 \mu \mathrm{g} /$ disk $)$ & $87.9 \%(58)$ & $12.2 \%(8)$ & $93.5 \%(171)$ & $6.5 \%(12)$ \\
\hline & CTX $(30 \mu \mathrm{g})$ & $84.8 \%(56)$ & $15.2 \%(10)$ & $84 \%(154)$ & $15.8 \%(29)$ \\
\hline & SAM $(20 \mu \mathrm{g})$ & $18.2 \%(12)$ & $81.8 \%(54)$ & $17.48 \%(32)$ & $82.5 \%(151)$ \\
\hline \multirow[t]{2}{*}{ Quinolones } & $\operatorname{LEV}(5 \mu \mathrm{g})$ & $90.9 \%(60)$ & $9.1 \%(6)$ & $96.1 \%(176)$ & $3.8 \%(7)$ \\
\hline & CIP $(5 \mu \mathrm{g})$ & $89.4 \%(59)$ & $10.6 \%(7)$ & $91.2 \%(167)$ & $8.75 \%(16)$ \\
\hline \multirow[t]{2}{*}{ Aminoglycosides } & CN $(10 \mu \mathrm{g})$ & $81.8 \%(54)$ & $18.2(12)$ & $87.4 \%(160)$ & $12.56 \%(23)$ \\
\hline & AK $(30 \mu \mathrm{g})$ & $83.3 \%(55)$ & $16.7 \%(11)$ & $93, .4 \%(171)$ & $6.55 \%(12)$ \\
\hline
\end{tabular}

$A x=$ Amoxicillin, Am=Ampicillin, $C x=$ Cefoxitin, Fox, IMP=Imipenem, CTX=Cefotaxime, AM/SAM: Ampicillin/sulbactam, $\mathrm{LEV}=$ Levofloxacin, $\mathrm{CIP}=$ Ciprofloxacin, $\mathrm{CN}=$ Gentamicin, $\mathrm{AK}=$ Amikacin, $\mathrm{MET}=$ Methicillin, *Salmonella spp. isolates $(n=66)(100 \% R)=(42$ highly resistant isolates +24 isolates with low resistance) A: $E$. coli isolates $(n=183)(100 \%$ $\mathrm{R})=(113$ highly resistant isolates +70 isolates with low resistance $), E$. coli=Escherichia coli

Table-5: Growth of bacteria in different concentrations of plant extracts and biosynthetic AuNPs.

\begin{tabular}{|c|c|c|c|c|c|}
\hline Name & $10 \mu \mathrm{g} / \mathrm{mL}$ & $20 \mu \mathrm{g} / \mathrm{mL}$ & $40 \mu \mathrm{g} / \mathrm{mL}$ & $60 \mu \mathrm{g} / \mathrm{mL}$ & $80 \mu \mathrm{g} / \mathrm{mL}$ \\
\hline A. herb-alba and M. alba & - & - & - & + & + \\
\hline A. herb-alba and M. alba AuNPs & + & + & + & + & + \\
\hline +ve control* & + & + & + & + & + \\
\hline -ve control** & - & - & - & - & - \\
\hline
\end{tabular}

*: Positive control (+ve)=Color change (red to pale yellow) indicating growth of E. coli and Salmonella, **: Negative control $(-\mathrm{ve})=$ No change in color (red) indicating the absence of growth of E. coli and Salmonella. E. coli=Escherichia coli, A. herba-alba=Artemisia herba-alba, M. alba=Morus alba, AuNPs=Gold nanoparticles

The successful biosynthesis of $A$. herba-alba and M. alba AuNPs after adding a mixture of $A$. herba-alba and $M$. alba leaf aqueous extracts was indicated by a change in solution color from yellow to purple/dark red and dark brown, signifying AuNP formation (Figure-3). This was due to phytochemical substances in the aqueous extract, which are responsible for the creation of a coating on the AuNPs, as described previously by Abdel-Kareem and Zohri [60].

The formation of AuNPs was confirmed by UV spectrophotometry at a wavelength of 520$570 \mathrm{~nm}$ based on surface plasmon resonance (SPR), as shown in Figure-4, and reported by Sundararajan and Kumari [61]. Synthesized AuNPs produced using Pogostemon benghalensis showed local SPR bands at $535-538 \mathrm{~nm}$ and $510-560 \mathrm{~nm}$. In addition, the AuNPs were further characterized by TEM and micrography, demonstrating that they were small and spherical, with small and large aggregations and an average size of $\sim 10-42 \mathrm{~nm}$, as shown in Figure-5a-c. The spherical AuNPs can form at the beginning of the reaction, which then aggregates together due to the presence of a large amount of reducing agents in the biomass. This is in agreement with a previous study by Sundararajan and Kumari [61] in which different sizes of Pityriasis alba AuNPs were prepared and shown to have average sizes of 20.65 and $36.05 \mathrm{~nm}$. This finding is also in agreement with the previous studies $[61,62]$ that found that phytochemicals can effectively stabilize smaller AuNPs with an average size of $7 \mathrm{~nm}$. As shown in Figure-5d, AuNPs were confirmed by selected area electron diffraction analysis. The micrograph showed spherical AuNPs in clear lattice fringes with bright circular rings corresponding to 5 to $1 \mathrm{~nm}$ planes. Different sets of spots could be identified from this diffraction pattern, as shown in Figure-5d. AuNPs similarly showed strong intensity at the 5-50 nm plane, with four concentric rings being observed in the AuNPs, indicating their crystalline nature. A. herba-alba and M. alba AuNPs had the maximum inhibitory effects on $E$. coli and Salmonella spp. with highest inhibition zone diameter and minimum inhibitory concentrations of $23 \mathrm{~mm}$ and $3.125 \mathrm{~g} / \mathrm{mL}$, respectively, for $E$. coli. This may have been due to the thin wall of the peptidoglycan layer in Gram-negative bacteria, which allow AuNPs to easily enter the cytoplasm, as shown in Figures- 6 and 7. These results are in agreement with the previous studies $[62,63]$ in which it was described that AuNPs have antibacterial activity. The antibacterial effects of A. herba-alba and M. alba AuNPs with different concentrations were higher than A. herba-alba and M. alba leaf extract against MDR E. coli and Salmonella spp., as shown in Table-5. This is the first study on the biosynthesis of AuNPs using a mixture of A. herba-alba and $M$. alba leaf extracts, the effects of which may be due to their flavonoids, tannins, and polyphenolic compounds. This composition can explain their strong reducing activity to promote the formation of NPs. Finally, A. herba-alba and M. alba AuNPs have antibacterial effects against MDR E. coli and Salmonella spp. that are resistant to traditional antibiotics. 


\section{Conclusion}

Bacterial resistance is one of the most important threats to animal health in the $21^{\text {st }}$ century, with bacterial cells developing resistance to one or more different antibiotics. Our study demonstrated the prevalence of MDR E. coli and Salmonella spp. isolated from different ruminants suffering from respiratory signs, diarrhea, and mastitis. The total rate of resistance to beta-lactam antibiotics in $E$. coli was $61.2 \%$, while that in Salmonella was $63.6 \%$. AuNPs were successfully biosynthesized using a mixture of aqueous leaf extracts of $A$. herba-alba and M. alba. They exhibited a particle size of 10-42 nm and exerted antibacterial effects on MDR E. coli and Salmonella spp. Alongside efforts to overcome the increasing rate of MDR bacteria in ruminants through several options, including improved animal hygiene and sanitation, as well as rapid and accurate diagnosis, NPs as alternative therapeutic agents are vital for effective treatment. Finally, NPs are the most promising strategy to overcome microbial drug resistance.

\section{Authors' Contributions}

AMA, AAA, ESI, and GSGZ: Designed the experiment and carried out the laboratory work. AAG: Contributed to the laboratory work and participated in drafting the manuscript. All authors read and approved the final manuscript.

\section{Acknowledgments}

We would like to acknowledge National Research Centre, Dokki, Egypt, for facilities and funds (Project No \# 12020231 \#).

\section{Competing Interests}

The authors declare that they have no competing interests.

\section{Publisher's Note}

Veterinary World remains neutral with regard to jurisdictional claims in published institutional affiliation.

\section{References}

1. Prestinaci, F., Pezzotti, P. and Pantosti, A. (2015) Antimicrobial resistance: A global, multifaceted phenomenon. Pathog. Glob. Health, 109(7): 309-318.

2. Acharya, K.P. and Wilson, R.T. (2019) Antimicrobial resistance in Nepal. Front. Med., 6(5): 105.

3. Abdalhamed, A.M., Ghazy, A.A. and Zeedan, G.S.G. (2021) Studies on multidrug-resistance bacteria in ruminants with special interest on antimicrobial resistance genes. Adv. Anim. Vet. Sci., 9(6): 835-844.

4. Zalewska, M., Błażejewska, A., Czapko, A. and Popowska, M. (2021) Antibiotics and antibiotic resistance genes in animal manure-consequences of its application in agriculture. Front. Microbiol., 12: 640-661.

5. Pavlovic, S., Kotur, N., Stankovic, B., Zukic, B., Gasic, V. and Dokmanovic, L. (2019) Pharmacogenomic and pharmacotranscriptomic profiling of childhood acute lymphoblastic leukemia: Paving the way to personalized treatment. Genes, 10(3): 191.

6. Muktar, Y., Mamo, G., Tesfaye, B. and Belina, D. (2015)
A review on major bacterial causes of calf diarrhea and its diagnostic method. J. Vet. Med. Anim. Health, 7(5): 173-185.

7. Leung, M.C. (2019) Synthesis and Development of Antibiotic Adjuvants to Restore Antimicrobial Activity Against Resistant Gram-Negative Pathogens (Doctoral Dissertation)

8. Saliu, E.M., Zentek, J. and Vahjen, W. (2020) In vitro conjugation kinetics of $\mathrm{AmpC}$, broad spectrum and extended-spectrum beta-lactamase-producing Escherichia coli donors and various Enterobacteriaceae recipients. BMC Microbiol., 20(1): 133.

9. Okpa, B.O., Gberikon, G.M., Aguoru, C.U. and Ogbonna, I.O. (2020) ESBL production and multidrug resistance of Salmonella serovars isolates in Benue state. Am. J. Mol. Biol., 10(3): 200.

10. Minakshi, P., Kumar, R., Ghosh, M., Brar, B., Barnela, M. and Lakhani, P. (2020) Application of polymeric Nanomaterials in management of inflammatory bowel disease. Curr. Top. Med. Chem., 20(11): 982-1008.

11. Shukla, A.K. and Iravani, S., editors. (2018) Green Synthesis, Characterization and Applications of Nanoparticles. Elsevier, Amsterdam, Netherlands.

12. Patil, P.M. and Bohara, R.A. (2020) Nanoparticles impact biomedical waste management. Waste Manag. Res., 38(11): 1189-1203.

13. Gabrielyan, L., Badalyan, H., Gevorgyan, V. and Trchounian, A. (2020) Comparable antibacterial effects and action mechanisms of silver and iron oxide nanoparticles on Escherichia coli and Salmonella typhimurium. Sci. Rep., 10(1): 1-12.

14. Subramaniam, J., Murugan, K., Panneerselvam, C., Kovendan, K., Madhiyazhagan, P., Dinesh, D., Kumar, P.M., Chandramohan, B., Suresh, U., Rajaganesh, R., Alsalhi, M.S., Devanesan, S., Nicoletti, M., Canale, A. and Benelli, G. (2016) Multipurpose effectiveness of Couroupita guianensis-synthesized gold nanoparticles: High antiplasmodial potential, field efficacy against malaria vectors and synergy with Aplocheilus lineatus predators. Environ. Sci. Pollut. Res., 23(8): 7543-7558.

15. Yadav, B. and Tyagi, R.D. (2020) Development of molecular methods to detect and control emerging drug-resistance pathogens. In: Current Developments in Biotechnology and Bioengineering. p377-419.

16. Ruddaraju, L.K., Pammi, S.V.N., Guntuku, G.S., Padavala, V.S. and Kolapalli, V.R.M. (2020) A review on anti-bacterial to combat resistance: From the ancient era of plants and metals to present and future perspectives of green Nanotechnological combinations. Asian J. Pharm. Sci., 15(1): 42-59.

17. Perera, A. (2015) Escherichia coli (E. coli) O157 and Non-O157 among Ruminants in Peninsular Malaysia: Pathogenicity, Antibiotic Resistance, and Survival Under Sub-Lethal Stress Conditions (Doctoral Dissertation, Monash University)

18. Tanih, N.F., Sekwadi, E., Ndip, R.N. and Bessong, P.O. (2015) Detection of pathogenic Escherichia coli and Staphylococcus aureus from cattle and pigs slaughtered in abattoirs in Vhembe district, South Africa. ScientificWorldJournal, 2015: 195972.

19. Abdalhamed, A.M., Zeedan, G.S.G. and Zeina, H.A.A. (2018) Isolation and identification of bacteria causing mastitis in small ruminants and their susceptibility to antibiotics, honey, essential oils, and plant extracts. Vet. World., 11(3): 355-362.

20. Tawyabur, M., Islam, M., Sobur, M., Hossain, M., Mahmud, M., Paul, S., Hossain, M.T., Ashour, H.M. and Rahman, M.T. (2020) Isolation and characterization of multidrug-resistant Escherichia coli and Salmonella spp. from healthy and diseased turkeys. Antibiotics, 9(11): 770.

21. Abdel-Raheem W.R., Abdel-Raheem, S.M., Al-Marri, T.M., Alaql, F.A. and Fayez, M.M. (2020) Isolation and identification of extended-spectrum $\beta$-lactamases (ESBLs) 
Escherichia coli from minced camel meat in Eastern province, Saudi Arabia. Thai J. Vet. Med., 50(2): 155-161.

22. Islam, M.K., Kabir, S.L., Haque, A.Z., Sarker, Y.A. and Sikder, M.H. (2018) Molecular detection and characterization of Escherichia coli, Salmonella spp. and Campylobacter spp. isolated from broiler meat in Jamalpur, Tangail, Netrokona and Kishoreganj districts of Bangladesh. Afr. $J$. Microbiol. Res., 12(32): 761-770.

23. Clinical and Laboratory Standards Institute (CLSI). (2012) Performance standards for antimicrobial susceptibility testing: Sixteenth Informational Supplement No. M100-S20. $30^{\text {th }}$ ed. CLSI, United States.

24. Moghadam, M.N., Naderifar, S., Zolfaghari, M.R., Amel Jamehdar, S. and Hashemi, M. (2020) Pattern of antibiotic susceptibility and detection of CTX-M-type extended-spectrum beta-lactamases (ESBLs) in urinary isolates of Klebsiella pneumoniae in Mashhad. Daneshvar Med., 19(5): 29-36.

25. King, T.L. and Schmidt, S. (2017) Assessment of three indigenous South African herbivores as potential reservoirs and vectors of antibiotic-resistant Escherichia coli. Eur. J. Wildl. Res., 63(3): 44.

26. Vázquez-López, R., Solano-Gálvez, S., León-Chávez, B.A., Thompson-Bonilla, M.R., Guerrero-González, T., GómezConde, E., Martínez-Fong, D. and González-Barrios, J.A. (2018) Characterization of gene families encoding beta-lactamases of gram-negative rods isolated from ready-to-eat vegetables in Mexico city. High Throughput, 7(4): 36.

27. Zeedan, G.S.G., Abdalhamed, A.M., Ibrahim, E.S., El-Sadawy, H.A.F. (2018) Antibacterial efficacy of green silver nanoparticles against bacteria isolated from calf diarrhea. Asian J. Epidemiol., 11(2): 65-73.

28. Azman, A.A., Nadiah, N., Rosandy, A.R., Alwi, A., Kamal, N. And Mohd, R. (2021) Antimicrobial Activity and LC-MS data comparison from lichen Parmotrema praesorediosum in Bangi, Selangor, Malaysia. Sains Malays., 50(2): 383-393.

29. Argudín, M.A., Deplano, A., Meghraoui, A., Dodémont, M., Heinrichs, A., Denis, O. and Roisin, S. (2017) Bacteria from animals as a pool of antimicrobial resistance genes. Antibiotics, 6(2): 12.

30. Algammal, A.M., El-Sayed, M.E., Youssef, F.M., Saad, S.A., Elhaig, M.M., Batiha, G.E., Hozzein, W.N. and Ghobashy, M.O.I. (2020) Prevalence, the antibiogram and the frequency of virulence genes of the most predominant bacterial pathogens incriminated in calf pneumonia. $A M B$ Express, 10(1): 1-8.

31. de Oliveira-Filho, R.D., de Azevedo Moreira, R. and Nogueira, N.A.P. (2018) Biological activities and pharmacological applications of cyclodextrins complexed with essential oils and their volatile components: A systematic review. Curr. Pharm. Des., 24(33): 3951-3963.

32. Amat, S. (2019) Development of Intranasal Bacterial Therapeutics to Mitigate the Bovine Respiratory Pathogen Mannheimia haemolytica. University of Calgary, Canada.

33. Santos, A.C.M., Silva, R.M., Valiatti, T.B., Santos, F.F., Santos-Neto, J.F., Cayô, R., Streling, A.P., Nodari, C.S., Gales, A.C., Nishiyama, M.Y. Jr., Carvalho, E. and Gomes, T.A.T. (2020) Virulence potential of a multidrug-resistant Escherichia coli strain belonging to the emerging clonal group ST101-B1 isolated from bloodstream infection. Microorganisms, 8(6): 827.

34. Hang, B.P.T., Wredle, E., Börjesson, S., Sjaunja, K.S., Dicksved, J. and Duse, A. (2019) High level of multidrug-resistant Escherichia coli in young dairy calves in Southern Vietnam. Trop. Anim. Health Prod., 51(6): 1405-1411.

35. Kates, A.E., Dalman, M., Torner, J.C. and Smith, T.C. (2019) The nasal and oropharyngeal microbiomes of healthy livestock workers. PLoS One, 14(3): e 0212949.

36. Abdel-Azeem, A.M., Abo Nahas, H.H., El-Azeem, A. and Ahmed, M. (2020) Mapping fungal ignorance: Checklists of fungi and El-Ghareeb, fungal-like organisms known for
Egypt in two centuries. Microb. Biosyst., 5(1): 115-119.

37. Shabana, I.I., Bouqellah, N.A. and Zaraket, H. (2017) Investigation of viral and bacterial enteropathogens of diarrheic sheep and goats in Medina, Saudi Arabia. Trop. Biomed., 34(4): 944-955.

38. Das, M., Deka, D.K., Sarmah, A.K., Sarmah, P.C. and Islam, S. (2018) Gastrointestinal parasitic infections in cattle and swamp buffalo of Guwahati, Assam, India. Indian J. Anim. Res., 52(12): 1732-1738.

39. Zeedan, G.S., Abdalhamed, A.M., Abdeen, E., Ottai, M.E. and Abdel-Shafy, S. (2014) Evaluation of antibacterial effect of some Sinai medicinal plant extracts on bacteria isolated from bovine mastitis. Vet. World., 7(11): 991-998.

40. Sobur, M.A., Sabuj, A.A.M., Sarker, R., Rahman, A.T., Kabir, S.L. and Rahman, M.T. (2019) Antibiotic-resistant Escherichia coli and Salmonella spp. associated with dairy cattle and farm environment having public health significance. Vet. World, 12(7): 984.

41. Abdalhamed, A.M., Ghazy, A.A. and Zeedan, G.S.G. (2021) Studies on multidrug-resistance bacteria in ruminants with special interest on antimicrobial resistances genes. $A d v$. Anim. Vet. Sci., 9(6): 835-844.

42. McKay, S., Sawant, P., Fehlberg, J. and Almenar, E. (2021) Antimicrobial activity of orange juice processing waste in powder form and its suitability to produce antimicrobial packaging. Waste Manag., 120(2): 230-239.

43. Lindsey, R.L., Garcia-Toledo, L., Fasulo, D., Gladney, L.M. and Strockbine, N. (2017) Multiplex polymerase chain reaction for identification of Escherichia coli, Escherichia albertii and Escherichia fergusonii. J. Microbial. Methods, 140(8): 1-4.

44. Titilawo, Y., Obi, L. and Okoh, A. (2015) Antimicrobial resistance determinants of Escherichia coli isolates recovered from some rivers in Osun State, South-Western Nigeria: Implications for public health. Sci, Total Environ, 523: 82-94.

45. Ali, E., Islam, M.S., Hossen, M.I., Khatun, M.M. and Islam, M.A. (2021) Extract of neem (Azadirachta indica) leaf exhibits bactericidal effect against multidrug-resistant pathogenic bacteria of poultry. Vet. Med. Sci., 7(5): 1921-1927.

46. Novais, A., Liu, X., Antimicrobials, R., Liu, X., Thungrat, K. and Boothe, D. M. (2018) Objective: The aim of this study was to explore the occurrence and molecular characteri zation of extended-spectrum $\beta$-lactamases (ESBL), plasmid-mediated AmpC $\beta$-lactamase $(\mathrm{pAmpC})$ and carbapenemases among ESBL-producing multidrug-resistant (MDR) Escherichia coli from dogs and cats in the United States. Methods: Of $2443 E$. coli isolated from dogs and cats collected between August 2009. Genet. Acquir. Antimicrob. Resist. Anim. Zoonotic Pathog., 203 (2018): 130-139.

47. Mthembu, T.P., Zishiri, O.T. and El Zowalaty, M.E. (2019) Molecular detection of multidrug-resistant Salmonella isolated from livestock production systems in South Africa. Infect. Drug Resist., 12 (2019): 3537

48. Chamlakhorn, W., Phuektes, P., Khang-Air, S. and Angkititrakul, S. (2021) Prevalence, genetic characterization, and antimicrobial resistance of Salmonella isolated from meat goats in the Northeastern region of Thailand. Vet. Integr. Sci., 19(3): 363-378.

49. Pribul, B.R., Festivo, M.L., Rodrigues, M.S., Costa, R.G., Rodrigues, E.C.D., de Souza, M. and Rodrigues, D.D.P. (2017) Characteristics of quinolone resistance in Salmonella spp. isolates from the food chain in Brazil. Front. Microbial., 8(2017): 299.

50. Bourély, C., Fortané, N., Calavas, D., Leblond, A. and Gay, É. (2018) Why do veterinarians ask for antimicrobial susceptibility testing. A qualitative study exploring determinants and evaluating the impact of antibiotic reduction policy. Prev. Vet. Med., 159 (2018): 123-134.

51. Bedkelabou, A.E.P., Talaki, E., Dolou,M., Diouf, A., and Alambedil, R.B. (2020) Antibiotic resistance of 
enterobacteria (Escherichia coli, Klebsiella spp. and Salmonella spp) isolated from healthy poultry and pig farms in a peri-urban area of Lome, Togo. Afr. J. Microbiol. Res., 14(12): 657-666.

52. Zhu, Y., Lai, H., Zou, L., Yin, S., Wang, C., Han, X., Xia, X., Hu, K., He, L., Zhou, K., Chen, S., Ao, X. and Liu, S. (2017) Antimicrobial resistance and resistance genes in Salmonella strains isolated from broiler chickens along the slaughtering process in China. Int. J. Food Microbiol., 259(10): 43-51.

53. Giuriatti, J., Stefani, L.M., Brisola, M.C., Crecencio, R.B., Bitner, D.S. and Faria, G.A. (2017) Salmonella Heidelberg: Genetic profile of its antimicrobial resistance related to extended-spectrum $\beta$-lactamases (ESBLs). Microb. Pathog., 109(7): 195-199.

54. Ogunrinu, O.J., Norman, K.N., Vinasco, J., Levent, G., Lawhon, S.D., Fajt, V.R., Volkova, V.V., Gaire, T., Poole, T.L., Genovese, K.J., Wittum, T.E. and Scott, H.M. (2020) Can the use of older-generation beta-lactam antibiotics in livestock production over-select for beta-lactamases of greatest consequence for human medicine? An in vitro experimental model. PLoS One, 15(11): e0242195.

55. Dong, N., Li, Y., Zhao, J., Ma, H., Wang, J., Liang, B., Du, X., Wu, F., Xia, S., Yang, X., Liu, H., Yang, C., Qiu, S., Song, H., Jia, L., Li Y. and Sun, Y. (2020) The phenotypic and molecular characteristics of antimicrobial resistance of Salmonella enterica subsp. enterica serovar Typhimurium in Henan province, China. BMC Infect. Dis., 20(1): 1-11.

56. Bush, K. and Bradford, P.A. (2020) Epidemiology of $\beta$-lactamase-producing pathogens. Clin. Microbial. Rev., 33(2): e00047-e00119.
57. Vrancianu, C.O., Popa, L.I., Bleotu, C. and Chifiriuc, M.C. (2020) Targeting plasmids to limit acquisition and transmission of antimicrobial resistance. Front. Microbiol., 11(2020): 761

58. Awosile, B.B. (2017) Antimicrobial Resistance Studies from Atlantic Canada with a Focus on Extended-Spectrum Cephalosporin Resistance in Dairy Cattle and Humans.

59. Rónavári, A., Igaz, N., Adamecz, D.I., Szerencsés, B., Molnar, C., Kónya, Z., Pfeiffer, I. and Kiricsi, M. (2021) Green silver and gold nanoparticles: Biological synthesis approaches and potentials for biomedical applications. Molecules, 26(4): 844.

60. Abdel-Kareem, M.M. and Zohri, A.A. (2018) Extracellular mycosynthesis of gold nanoparticles using Trichoderma hamatum: Optimization, characterization and antimicrobial activity. Lett. Appl. Microbial., 67(5): 465-475.

61. Sundararajan, B. and Kumari, B.R. (2017) Novel synthesis of gold nanoparticles using Artemisia vulgaris L. leaf extract and their efficacy of larvicidal activity against dengue fever vector Aedes aegypti L. J. Trace Elem. Med. Biol., 43(9): 187-196.

62. Sasidharan, S. and Pottail, L. (2020) Anti-bacterial and skin-cancer activity of AuNP, rGO and AuNP-rGO composite using Hemigraphis alternata (Burm. F.) T. anderson. Biocatal. Agric. Biotechnol., 25(2): 101596.

63. Herrera-Sánchez, M.P., Castro-Vargas, R.E., Fandiñode-Rubio, L.C., Rodríguez-Hernández, R. and RondónBarragán, I.S. (2021) Molecular identification of fluoroquinolone resistance in Salmonella spp. isolated from broiler farms and human samples obtained from two regions in Colombia. Vet. World, 14(7): 1767-1773. 